\title{
AMS-GRAPHITE TARGET PRODUCTION METHODS AT THE WOODS HOLE OCEANOGRAPHIC INSTITUTION DURING 1986-1991 ${ }^{1}$
}

\author{
ALAN R. GAGNON and GLENN A. JONES
}

Geology and Geophysics Department, Woods Hole Oceanographic Institution

Woods Hole, Massachusetts 02543 USA

ABSTRACT. In July 1986, an AMS radiocarbon target preparation laboratory was established at the Woods Hole Oceanographic Institution to produce graphite to be analyzed at the NSF-Accelerator Facility for Radioisotope Analysis at the University of Arizona (Tucson). By June 1991, 923 graphite targets had been prepared and 847 analyzed. Our lab procedures during this time included the careful documentation of weights of all starting samples, catalysts and final graphite yields, as well as the volume of $\mathrm{CO}_{2}$ gas evolved during $\mathrm{CaCO}_{3}$ hydrolysis or closed-tube organic carbon combustions. From these data, we evaluate the methods used in general and in our lab.

\section{INTRODUCTION}

We present here the sample preparation and graphitization procedures used at the Woods Hole Oceanographic Institution (WHOI) AMS-Graphite Target Preparation Laboratory from July 1986 through June 1991. The methods are based on those developed by Jull et al. (1986) and Slota et al. (1987) and modified slightly by Jones et al. (1989). We describe additional refinements or changes to these methods. All graphite produced during this period was analyzed at the NSFAccelerator Facility for Radioisotope Analysis at the University of Arizona (Linick et al. 1986). L. Toolin from the Arizona TAMS facility assisted with the initial design and setup of the glass vacuum lines for this lab. The initial line was designed to produce and quantify $\mathrm{CO}_{2}$ generated from either $\mathrm{CaCO}_{3}$ hydrolysis or closed-tube organic carbon combustion reactions and reduce the $\mathrm{CO}_{2}$ gas to graphite in two reactor ports (Fig. 1). By June 1988, we had expanded our capabilities to include extraction of dissolved inorganic carbon (DIC) from seawater and increased the number of graphite reactor ports to six. A typical work day consisted of graphitizing five carbonate or organic carbon samples and either an NBS oxalic acid I (OX I) or oxalic acid II (OX II) gas standard. We generated vacuum line blanks $\left({ }^{14} \mathrm{C}\right.$-"dead" carbonate) at the beginning, middle and end of each graphite target preparation batch run of $c a$. 100-120 targets.

Of the 923 targets produced from July 1986 to June 1991, 847 were AMS-dated at the Arizona facility. All targets produced after June 1991 were analyzed at the National Ocean Sciences Accelerator Mass Spectrometry (NOSAMS) Facility (Jones et al. 1990) located at the Woods Hole Oceanographic Institution. In July 1991, the lab was moved and integrated with the newly completed NOSAMS graphite preparation lab. We present summary results on $528 \mathrm{CaCO}_{3}$ hydrolysis reactions (497 AMS-dated), 144 closed-tube organic carbon combustion reactions (129 AMS-dated), and 38 DIC extractions from seawater (32 AMS-dated). We also present summary results for 170 NBS OX I and OX II standards (156 AMS-dated), $36 \mathrm{CaCO}_{3}$ hydrolysis blanks (27 AMS-dated) and 7 closed-tube organic carbon combustion blanks (6 AMS-dated).

Laboratory procedures during this time consisted of documenting and recording into a database the starting sample and catalyst weights, reactor port utilized, $\mathrm{CO}_{2}$ reaction pressures, final graphite yields and the volume of $\mathrm{CO}_{2}$ gas evolved by $\mathrm{CaCO}_{3}$ hydrolysis or closed-tube organic carbon combustion of the samples. Also included in the database are fields such as the date the sample

${ }^{1}$ This paper was presented at the 14th International Radiocarbon Conference, 20-24 May 1991, Tucson, Arizona. 


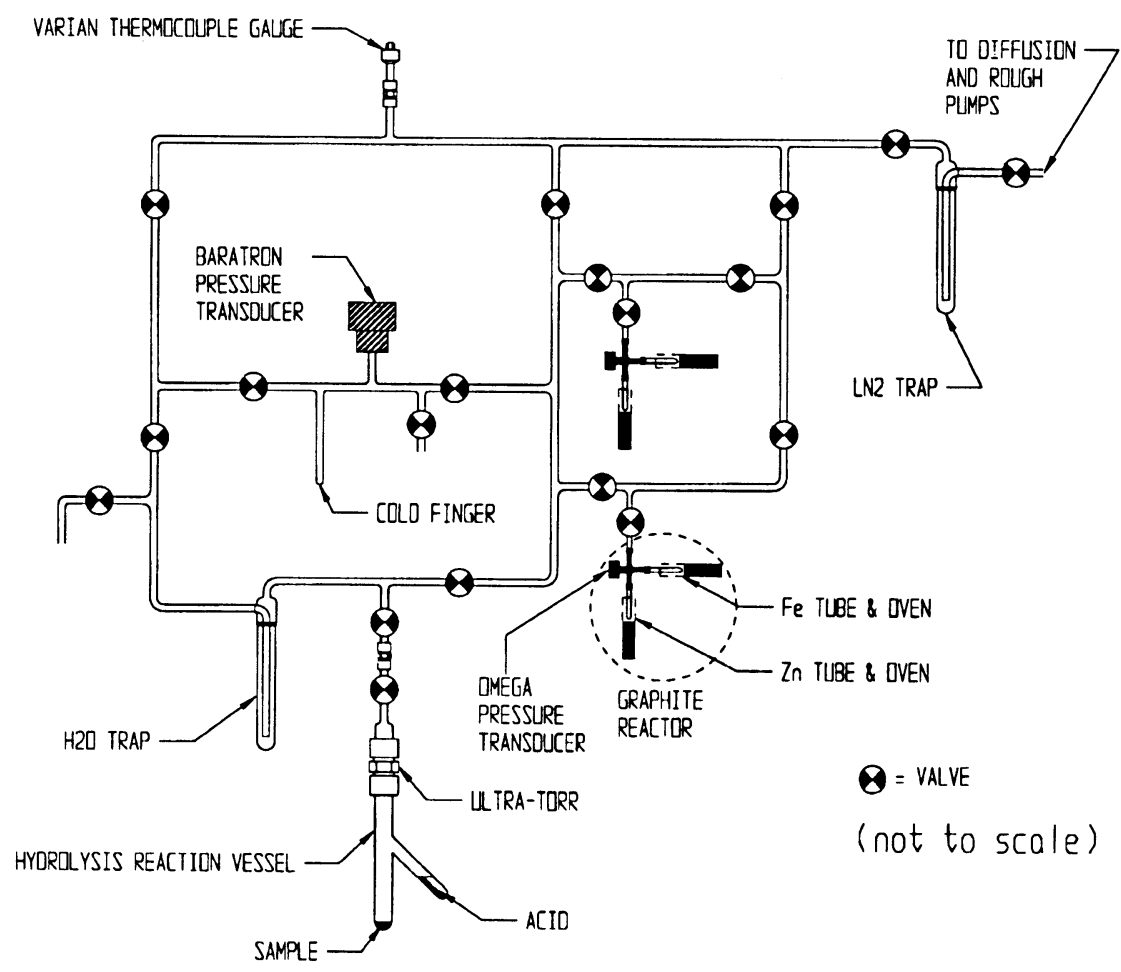

Fig. 1. Schematic of the initial WHOI graphite preparation vacuum line. Shown is the typical $\mathrm{CO}_{2}$ transfer setup for $\mathrm{CaCO}_{3}$ hydrolysis reaction prior to acidification of the sample.

was AMS-analyzed, the ${ }^{14} \mathrm{C}$ age and precision, fraction modern and precision and the corresponding Arizona AMS target accession numbers. Using this database, we can sort and calculate a wide range of parameters that allow us to evaluate the methods used in general and in our lab.

\section{METHODS}

\section{NBS Oxalic Acid Standards}

We made NBS oxalic acid standards using the wet digestion methods presented in Valastro, Land and Varela (1979). Our standards were made at the WHOI Radiocarbon Laboratory using the techniques outlined in Griffin and Druffel (1985). We synthesized 5 liters each of clean $\mathrm{CO}_{2}$ gas from NBS OX I and OX II. We used an approximate $3.05 \mathrm{cc}$ aliquot of $\mathrm{CO}_{2}$ gas, resulting in a 1.5 $\mathrm{mg}$ graphite target, for each oxalic acid graphite target produced. We used the same 5-liter bulbs of OX I and OX II CO 2 standards during the entire period, 1986-1991.

\section{$\mathrm{CaCO}_{3}$ Hydrolysis}

The primary carbonate sample types processed were open-ocean microfossil species of foraminifera (both benthonic and planktonic), miscellaneous macrofossil bivalve shell species and total carbonate from ocean sediments. These samples were weighed $\left(8-15 \mathrm{mg} \mathrm{CaCO}_{3}\right)$ and transferred to a glass reaction vessel (Fig. 1). We added $4 \mathrm{ml}$ of $85 \%$ phosphoric acid to the side arm of the reaction vessel, and connected a glass-plug vacuum valve to the vessel via a Cajon Ultra-Torr union. We connected the vessel to the vacuum line and applied a dewar containing a dry ice/isopropanol slush 
trap to the acid arm to contain water residing in the acid. The valve was opened slowly until vacuum was achieved, as indicated on a Varian 801 thermocouple gauge. The valve was closed, the vessel removed from the vacuum line and the acid warmed to ambient temperature. The vessel was tilted manually to allow the acid to flow from the side arm until it made contact with the carbonate. We added the acid slowly to prevent the sample from "splashing up" into the upper part of the reaction vessel. We then heated the acid/sample mixture to near boiling with a Bunsen burner every $30 \mathrm{~min}$ until we observed no reaction. Reaction time was usually ca. $2 \mathrm{~h}$.

Once the reaction was completed, the vessel was re-attached to the vacuum line, a dry ice/isopropanol slush trap was attached to the lower finger of the reaction vessel, a second dry ice/isopropanol slush trap was attached to the vacuum line, the reaction vessel was opened and the gas was transferred cryogenically for 3-4 min to a region of known volume. The $\mathrm{CO}_{2}$ was expanded in the known-volume region, warmed to ambient temperature, measured with an MKS Baratron 222BA pressure transducer and transferred directly to the graphite reactor (Fig. 1).

All carbonate blanks were made from a Pennsylvanian limestone obtained from the Arizona lab. From September 1986 to June $1989, \mathrm{CaCO}_{3}$ blanks were made without pretreatment (acid etching) of the sample. A $40-50 \mathrm{mg}$ sample was crushed, $\mathrm{ca}$. $10-15 \mathrm{mg}$ were acidified and the evolved $\mathrm{CO}_{2}$ was graphitized. The remaining $30-40 \mathrm{mg}$ of crushed carbonate were saved for the two remaining blanks associated with each batch run of 100 target preparations. This approach resulted in each successive blank giving increasingly higher backgrounds due to adsorption of atmospheric $\mathrm{CO}_{2}$ onto the carbonate. After May 1989, we implemented the following procedure for each blank produced. About $15-20 \mathrm{mg}$ limestone were placed in a precleaned beaker and acidified for 1-3 min with $10 \%$ organic-free $\mathrm{HCl}$ (Froelich 1990). The limestone was rinsed thoroughly with double-distilled water $\left(\mathrm{DDH}_{2} \mathrm{O}\right)$ (Froelich 1990) to remove the acid and placed in a $50^{\circ} \mathrm{C}$ oven until dry. A precleaned $\left(10 \% \mathrm{HCl}, \mathrm{DDH}_{2} \mathrm{O}\right.$ rinse) agate mortar and pestle were used to crush the sample to a fine powder. The powder was weighed $(10-15 \mathrm{mg})$, transferred to a reaction vessel and hydrolyzed according to the procedures outlined above. Any remaining $\mathrm{CaCO}_{3}$ powder was discarded.

\section{Closed-Tube Organic Carbon Combustion}

The primary organic carbon sample types were derived from total organic carbon and miscellaneous organic fragments in ocean sediments, wood fragments, insect parts and egg cases, and particulate organic matter from deep-ocean sediment traps. $\mathrm{CO}_{2}$ was generated from each sample using the methods outlined in LeFeuvre and Jones (1988), with slight adjustments by the authors. This combustion method was chosen from review of studies conducted by Leventhal (1976). These modifications follow closely the study performed by Swerhone et al. (1991), which showed this method to be scientifically viable, economical and simple to perform. All materials used for these analyses (i.e., beakers, syringes, tweezers and aluminum foil) were precleaned with $10 \% \mathrm{HCl}$ and baked at $550^{\circ} \mathrm{C}$ in a muffle furnace for $2 \mathrm{~h}$.

All sediments for ${ }^{14} \mathrm{C}$ organic carbon analysis were weighed and placed in a precleaned Pyrex beaker, acidified with $10 \%$ organic-free $\mathrm{HCl}$, filtered onto a prebaked $\left(600^{\circ} \mathrm{C}\right)$ quartz fiber filter $(5 \times 5 \mathrm{~mm})$ and rinsed with $\mathrm{DDH}_{2} \mathrm{O}$. The filter was wrapped lightly in precleaned aluminum foil and dried in a $50^{\circ} \mathrm{C}$ oven. Sample combustion tubes $(9 \mathrm{~mm}$ o.d. $\times 200$-mm-long Pyrex glass) were soaked overnight in Chromerge, rinsed with distilled water, then dried and baked at $550^{\circ} \mathrm{C}$ for 2 $\mathrm{h}$ in a muffle furnace. Two grams $\mathrm{CuO}$ (prebaked at $\left.850^{\circ} \mathrm{C}\right)$ and a silver foil strip $(4.0 \times 5.0 \mathrm{~mm}$, cleaned in $10 \% \mathrm{HCl}$, rinsed with methanol and baked at $550^{\circ} \mathrm{C}$ ) were added to the tube. The dried, filtered sample was rolled tightly using clean stainless-steel tweezers, and fitted into the combustion tube. The tube was re-attached to the vacuum line and flame-sealed in vacuo. Samples were 
combusted at $550^{\circ} \mathrm{C}$ for $5 \mathrm{~h}$ in a muffle furnace. After cooling slowly, the tubes were cracked under vacuum, evolved water vapor was trapped with a dry ice/isopropanol slush trap, the $\mathrm{CO}_{2}$ was cryogenically transferred to a region of known volume, and the frozen sample was opened to vacuum for 10-30 s to remove incondensibles. The $\mathrm{CO}_{2}$ was then measured manometrically with an MKS Baratron 222BA pressure transducer and transferred to a graphite reactor. Experiments performed on plant material by Swerhone et al. (1991) showed no significant fractionation in $\delta^{13} \mathrm{C}$ values utilizing this method.

All other material selected for organic carbon analysis was placed in a clean Pyrex beaker, acidified with $10 \%$ organic-free $\mathrm{HCl}$ and rinsed with $\mathrm{DDH}_{2} \mathrm{O}$. A $2 \% \mathrm{NaOH}$ solution was added, and the beaker placed in a $60^{\circ} \mathrm{C}$ constant-temperature water bath for $1 \mathrm{~h}$. To remove all humic acids, the $\mathrm{NaOH}$ step was repeated (discarding the supernatant, usually 2-4 times, but occasionally left overnight) until the solution remained clear. The sample was rinsed with $\mathrm{DDH}_{2} 0$, re-acidified with $10 \%$ organic-free $\mathrm{HCl}$, and rinsed again with $\mathrm{DDH}_{2} \mathrm{O}$ during filtering (as previously described). $\mathrm{CO}_{2}$ was generated by closed-tube combustion as outlined above.

To test the background of the closed-tube organic carbon combustion procedure, we generated $\sim 1.5$ $\mathrm{cc}$ of $\mathrm{CO}_{2}$ from the Pennsylvanian limestone in the same manner as outlined for carbonate blanks in the $\mathrm{CaCO}_{3}$ hydrolysis section. The $\mathrm{CO}_{2}$ evolved was transferred cryogenically to a Pyrex glass combustion tube containing the following precleaned ingredients; $2 \mathrm{~g} \mathrm{CuO}$, a strip of silver foil and a quartz fiber filter that had been rinsed with $\mathrm{DDH}_{2} \mathrm{O}$ and dried. The tube with $\mathrm{CO}_{2}$ was flamesealed in vacuo and combusted according to the procedures outlined above.

\section{DIC from Seawater}

We adapted methods described in Bard et al. (1987) to strip $\mathrm{CO}_{2}$ from seawater. Each sample for DIC ${ }^{14} \mathrm{C}$ analysis was drawn from a Niskin bottle, stored in a precleaned 1-liter glass bottle and poisoned with a saturated $\mathrm{HgCl}_{2}$ solution. We transferred 0.5 liter of the 1-liter sample to a stripping vessel. Ultra-pure helium was used as the carrier gas. We added $4 \mathrm{ml}$ of $85 \%$ phosphoric acid to the water, and the sample was bubbled in a helium atmosphere for $1 \mathrm{~h}$ at a flow rate of $0.10 \mathrm{cfh}$. The vacuum-line trapping sequence consisted of 1 dry-ice/isopropanol slush trap followed by 3 liquid nitrogen traps. After $1 \mathrm{~h}$, the helium was pumped away, and the $\mathrm{LN}_{2}$ traps were replaced by 3 dry-ice/isopropanol slush traps (to dry the $\mathrm{CO}_{2}$ thoroughly). The $\mathrm{CO}_{2}$ was transferred cryogenically to a region of known volume and measured manometrically with an MKS Baratron 222BA pressure transducer. Splits for ${ }^{13} \mathrm{C}$ analysis and an archive were saved in flame-sealed glass tubes. The ${ }^{14} \mathrm{C}$ split was transferred directly to a graphite reactor. Tests performed on samples of known $\mathrm{SCO}_{2}$ concentrations, measured coulometrically, showed that our technique recovers $>99.0 \%$ of the $\Sigma \mathrm{CO}_{2}$.

\section{Graphite Target Preparation}

The methods used follow closely those detailed in Slota et al. (1987). Glass tubing used in the reaction was precleaned with the following procedure: Vycor (quartz) and Pyrex tubing $(6 \mathrm{~mm}$ o.d. $\times 130 \mathrm{~mm}$ ) were soaked overnight in a Chromerge solution, and then baked for $3 \mathrm{~h}$ at $850^{\circ} \mathrm{C}$ for Vycor, and $550^{\circ} \mathrm{C}$ for Pyrex, in a muffle furnace. The Vycor tube was preweighed, 1-2 mg of 200 mesh Fe powder added, and the tube reweighed. About 50-80 mg of 300 mesh $\mathrm{Zn}$ powder was added to the Pyrex tube. The tubes were connected to the reactor via a $6.5 \mathrm{~mm}$ Cajon Ultra-Torr tee fitting with an attached Omega PX176 pressure transducer (Fig. 1). The reactor ovens were placed on the tubes and the catalyst and reagent roasted in vacuo for $20 \mathrm{~min}$. Reactor-oven temperatures were $650^{\circ} \mathrm{C}$ for $\mathrm{Fe}$ and $435^{\circ} \mathrm{C}$ for $\mathrm{Zn}$ (controlled by variable transformers). We 
removed the ovens, isolated the reactor from the vacuum pump and monitored the reactor pressure for 1-2 $\mathrm{h}$ to guarantee no leaks to atmosphere. A known amount of $\mathrm{CO}_{2}$ gas was transferred cryogenically to the reactor, brought to ambient room temperature and the pressure recorded. The $435^{\circ} \mathrm{C}$ oven was placed over the Pyrex tube containing the $\mathrm{Zn}$, so that the tip of the tube was located at the "hot spot" $\left( \pm 5^{\circ} \mathrm{C}\right)$ of the oven. We monitored the pressure until stable (ca. $\left.30 \mathrm{~min}\right)$. Residual gas analysis (RGA) performed on several reactions showed that most $\mathrm{CO}_{2}$ had dissociated to $\mathrm{CO}$ by this time (McNichol et al. 1992). The $650^{\circ} \mathrm{C}$ oven was then placed over the Vycor tube containing the $\mathrm{Fe}$, so that the tip of the tube was within the "hot spot" $\left( \pm 5^{\circ} \mathrm{C}\right)$. The reaction proceeded overnight, and was complete (typically, 7-10 h) when the pressure in the reactor returned to zero (Fig. 2), indicating a manometrically determined $100 \%$ yield. The ovens were removed from the tubes, and the reactor cooled to room temperature. Vacuum was broken slowly at the $\mathrm{Zn}$ tube Ultra-Torr connector, and the $\mathrm{Zn}$ tube discarded. The Fe tube (with graphite) was removed immediately and weighed. A graphite yield was determined gravimetrically. The tube containing graphite was then labeled, capped with parafilm and stored in a desiccator.

\section{RESULTS}

Having stored all of the graphite reaction values in a database file, we were able to determine a range of relations. As a check on the $\mathrm{CO}_{2}$-to-graphite reaction, several graphitizations were manometrically monitored overnight with the Omega PX176 pressure transducer connected to a HP9000 UNIX workstation via an HP3852 data acquisition control unit. A final pressure of zero would indicate a $100 \%$ yield. The reaction time for three different initial $\mathrm{CO}_{2}$ pressures of OX II

\section{NBS Oxalic Acid II}

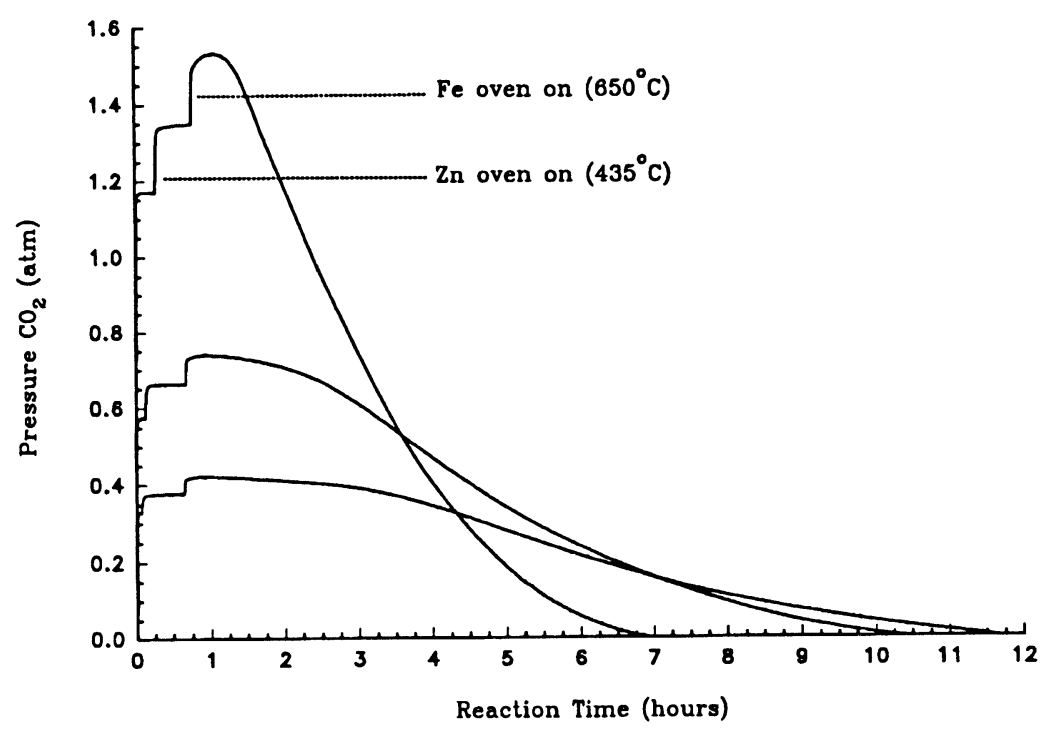

Fig. 2. Reaction times for catalytic reduction of $\mathrm{CO}_{2}$ to graphite using $\mathrm{Fe}-\mathrm{Zn}$. With a starting $\mathrm{CO}_{2}$ pressure of $1.1 \mathrm{~atm}(6.5 \mathrm{cc})$, the reaction was complete in $7.0 \mathrm{~h}$. The reaction time increased to $10.5 \mathrm{~h}$ by halving the $\mathrm{CO}_{2}$ pressure $(0.58 \mathrm{~atm}=3.25 \mathrm{cc})$. Reducing the $\mathrm{CO}_{2}$ to $0.25(0.33 \mathrm{~atm}=1.8 \mathrm{cc})$ further increases the reaction time to $11.6 \mathrm{~h}$. A manometrically determined $100 \%$ graphite yield was obtained from all three reactions. 
Woods Hole Graphites 045-969

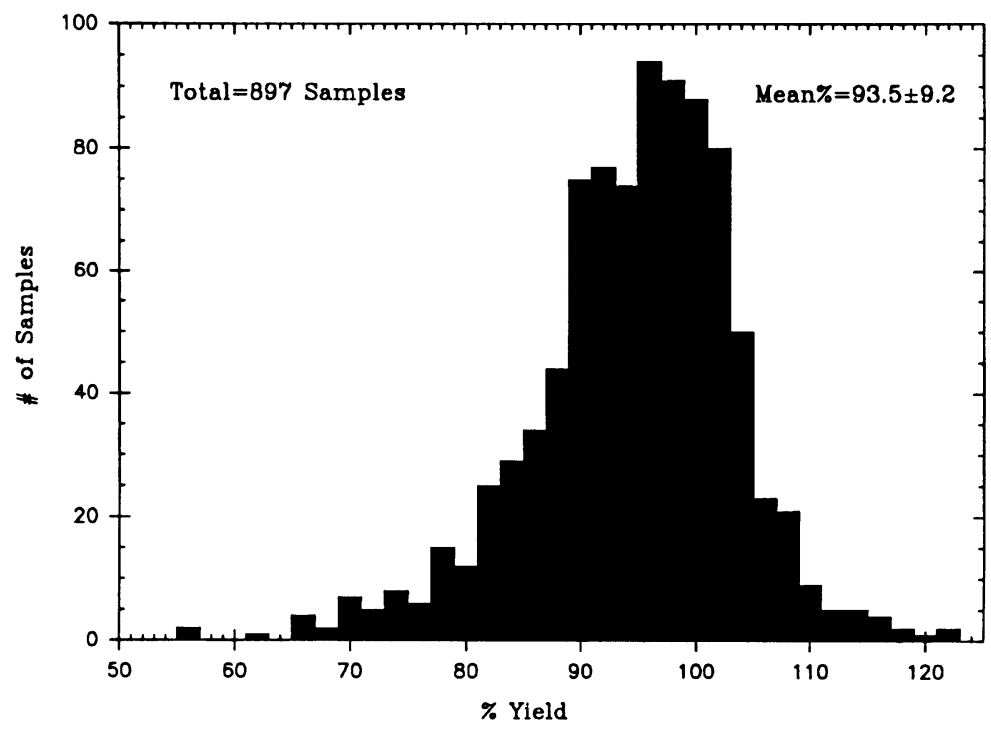

Fig. 3. Histogram of all Woods Hole graphite yields of samples produced between 1987 and 1991. Manometric measurements of the initial and final pressures for all samples indicate that all $\mathrm{CO}_{2}$ is converted to graphite; however, gravimetric measurements of the graphite suggest an average yield of $93.5 \%$. We believe the slightly lower yields calculated gravimetrically are due to preroasting and vacuum pumping on the iron catalyst and tube, which occurs after the iron has been weighed into the tube. Much of the scatter in the data is due to the precision limitations of the gravimetric measurements. Mean weight of graphites produced was $1.3 \pm 0.45 \mathrm{mg}$ where the precision of the analytical balance used was $\pm 0.05 \mathrm{mg}$ or $4 \%$ of the mean. Percent yields are calculated as actual weighed graphite divided by the theoretically calculated graphite as determined manometrically.

increased from $c a .7 \mathrm{~h}$ for initial pressures of $\sim 1.2 \mathrm{~atm}$ (STP) to $c a .12 \mathrm{~h}$ for initial pressures of $\sim 0.4$ atm (STP) (Fig. 2). The average $\mathrm{CO}_{2}$ pressure of samples analyzed at this lab from 1987-1991 was $0.6 \mathrm{~atm}$ (STP). Monitoring the reaction with $\mathrm{CO}_{2}$ evolved from closed-tube organic carbon combustion yielded a reaction time of $8-10 \mathrm{~h}$ for a nominal pressure of $0.8 \mathrm{~atm}$ (STP).

A comparison of the gravimetrically measured graphite $v s$. that calculated manometrically from the $\mathrm{CO}_{2}$ pressure gave a mean yield of $93.5 \pm 9.2 \%$ (Fig. 3). Monitoring the initial and final gas pressure within the reactors via the pressure transducer indicated a $100 \%$ conversion of $\mathrm{CO}_{2}$ to graphite. Samples were weighed immediately after vacuum was broken at the reactor to reduce moisture absorption from the atmosphere. Much of the scatter $( \pm 9.2 \%)$ can probably be attributed to weighing the increase of 1-2 mg (graphite yield) in a tube that initially weighed 4-5 g (typical weight of tube $+\mathrm{Fe}$ ) on an analytical balance that has an internal reproducibility of $\pm 0.05 \mathrm{mg}$. The difference between the mean manometric (100\%) and mean gravimetric $(93.5 \%)$ yields may be, in part, a result of preroasting and pumping on the iron catalyst after initial weighing.

On each target wheel run at the Arizona facility, there were 10 positions consisting of 8 samples, an OX I (position 1), and an OX II (position 6) standard. An OX II/OX I ratio was calculated for each wheel, and the mean value obtained from 75 pairs of OX II/OX I graphite targets produced in our lab between 1987 and 1991 was $1.292 \pm 0.012$ (Fig. 4). The OX II/OX I value used by the Arizona facility was 1.2909 (Donahue, Linick \& Jull 1990). Our standard method of interaction 


\section{WHOI NBS Oxalic Acid Ratios}

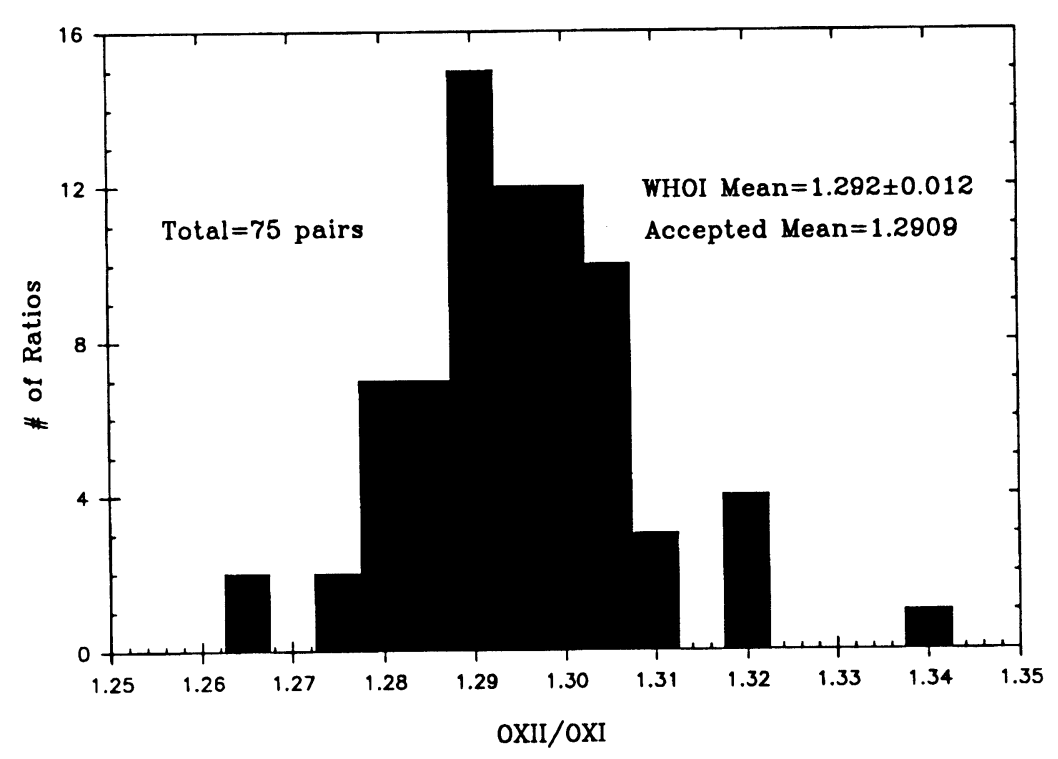

Fig. 4. Results of all Woods Hole NBS oxalic acid standard ratios obtained from 1987-1991. On each wheel of 10 WHOI targets analyzed at the Arizona TAMS facility, there is 1 OX I and 1 OX II standard. The WHOI OX II value is divided by the value of OXI ( $=1.046$ fraction modern), yielding a mean of $1.292 \pm 0.012$. The OX II/OX I ratio used by the Arizona facility was 1.2909 (Donahue, Linick \& Jull 1990). The differences in the ratios determined by the two labs are statistically insignificant.

with the Arizona facility was to produce 100 targets ( 10 wheels $=1$ WHOI batch run $)$ consisting of 75-76 unknown samples, 10 OX I standards, 10 OX II standards, $3 \mathrm{CaCO}_{3}$ hydrolysis blanks, and 1-2 closed-tube organic carbon combustion blanks.

Figures $5 \mathrm{~A}$ and $5 \mathrm{~B}$ show the precision $v$ s. the ${ }^{14} \mathrm{C}$ age (in ka $\mathrm{BP}$ ) for all Woods Hole graphite targets run at Arizona. Over $80 \%$ of the graphite targets analyzed were younger than $15 \mathrm{ka} \mathrm{BP}$ (Fig. 5B). The precision obtained for all Woods Hole graphite samples of near modern age, based largely on counting statistics and random laboratory error, is $0.6-0.7 \%$.

Figures $6 \mathrm{~A}$ and $6 \mathrm{~B}$ show histograms of uncorrected percent modern carbon (pMC) values for carbonate blanks analyzed before June 1989 and from June 1989 to June 1991, respectively. Before we began pretreating (acid-etching) our carbonate blank material in June 1989, as described in the methods section, our mean blank value was $0.556 \pm 0.37 \mathrm{pMC}$, with higher values obtained for increased time between the crushing of the blank material and graphitization (Fig. 6A). This increase probably results from adsorption of atmospheric $\mathrm{CO}_{2}$ on the crushed $\mathrm{CaCO}_{3}$ powder (i.e., large surface-to-volume ratio). After May 1989, the pre-etching of the carbonate blank material with $10 \%$ organic-free $\mathrm{HCl}$ for $1-3$ min before crushing decreased our $\mathrm{CaCO}_{3}$ blank value to 0.256 \pm 0.12 pMC (Fig. $6 \mathrm{~B}$ ). The results suggest that atmospheric $\mathrm{CO}_{2}$ can contribute to contamination of old $\mathrm{CaCO}_{3}$ samples, which, in turn, can result in erroneous ${ }^{14} \mathrm{C}$ values. Several tests of preetching $v s$. no treatment on foraminifera recovered from marine sediments show that pre-etching results in 2-3 ka older ages for samples near $30 \mathrm{ka} \mathrm{BP}(2.4 \mathrm{pMC})$. Our standard procedure is to pre-etch, with $10 \%$ organic-free $\mathrm{HCl}$, all $\mathrm{CaCO}_{3}$ samples estimated to be $>25 \mathrm{ka} \mathrm{BP}$ (<4.4 pMC). Our closed-tube organic carbon combustion blanks show an uncorrected value of $0.762 \pm 0.12$ 


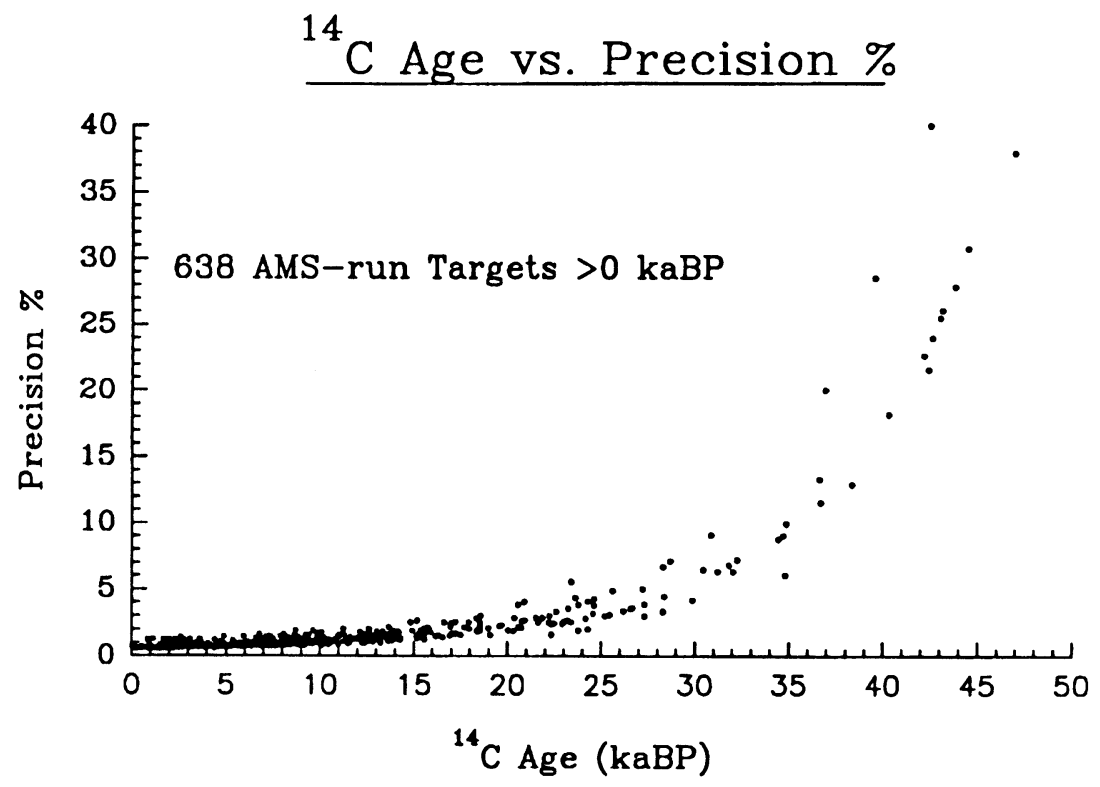

Fig. 5A. ${ }^{14} \mathrm{C}$ age $v s$. precision $\%$ for all targets produced at WHOI and run at the Arizona TAMS facility with ages $>0 \mathrm{ka}$ BP (excluding blanks). Precision $\%$ is calculated by dividing the value of fraction modern error by the actual fraction modern multiplied by 100 .



Fig. 5B. ${ }^{14} \mathrm{C}$ age (<15 ka BP) vs. precision \% showing only those samples in Figure $5 \mathrm{~A}$ that are younger than $15 \mathrm{ka} B P$. Note that sample precision approaches $\pm 0.6-0.7 \%$. 

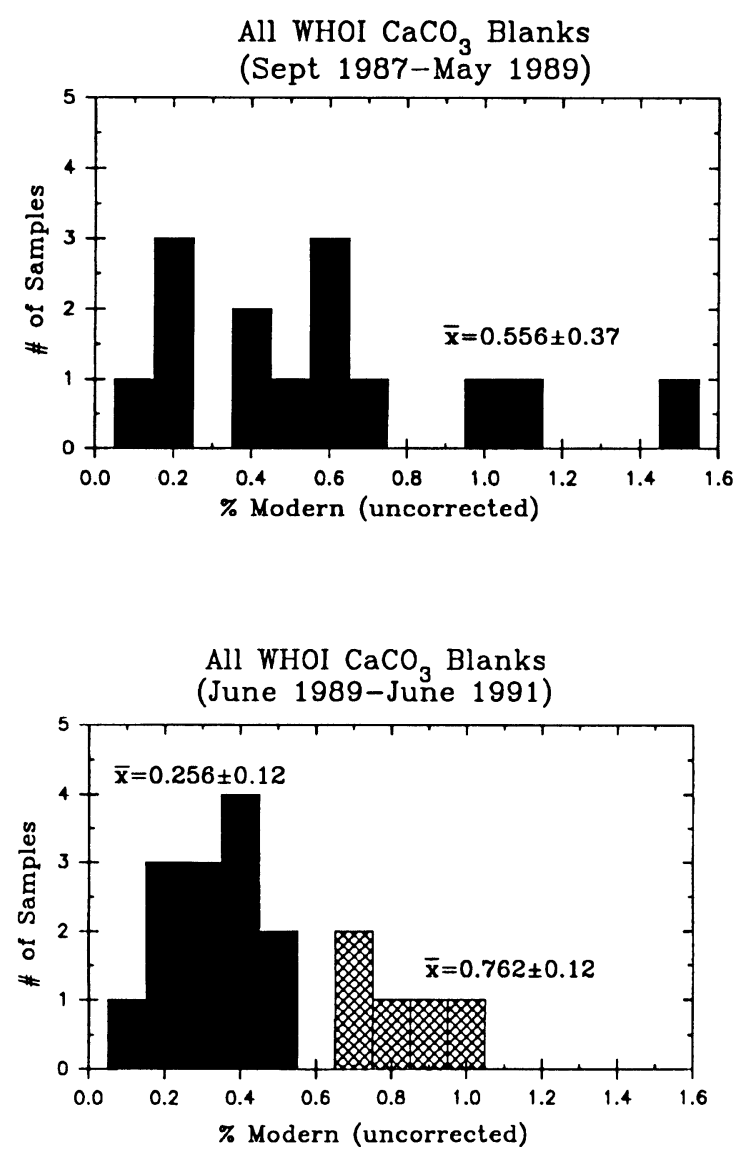

Fig. 6A. Uncorrected ${ }^{14} \mathrm{C} /{ }^{12} \mathrm{C}$ values for 14 WHOI $\mathrm{CaCO}_{3}$ blanks run before June 1989. Samples were not subjected to the pretreatment procedures outlined in the $\mathrm{CaCO}_{3}$ hydrolysis methods section. Our mean pMC during the period was $0.556 \pm 0.37$.
Fig. 6B. Uncorrected ${ }^{14} \mathrm{C} /{ }^{12} \mathrm{C}$ values for 13 WHOI $\mathrm{CaCO}_{3}$ blanks and 5 organic carbon blanks (hatched). All blanks made after May 1989 were subjected to the pretreatment procedures outlined in the $\mathrm{CaCO}_{3}$ hydrolysis methods section. Our mean pMC during the period was $0.256 \pm 0.12$ for $\mathrm{CaCO}_{3}$ and $0.762 \pm$ 0.12 for organic carbon blanks.

pMC. Our laboratory $\mathrm{CaCO}_{3}$ hydrolysis and closed-tube organic carbon combustion blank values are indistinguishable from similar results obtained in Arizona (Jull, personal communication).

\section{CONCLUSIONS}

Between July 1986 and June 1991, we produced 923 graphite targets at the Woods Hole Oceanographic AMS Graphite Preparation Lab using the methods of Slota et al. (1987). Our results are consistent with those obtained at the NSF-Arizona Accelerator Facility for Radioisotope Analysis, using the same methodology. We have also shown that the graphite yields obtained with these methods have a mean yield of $c a$. $94 \%$, with a reaction time of 7.0-12.0 h. Analysis of 75 pairs of OX I and OX II standards reveal an OX II/OX I ratio of $1.292 \pm 0.012$, which is in agreement with the value used by Arizona (Donahue, Linick \& Jull 1990). Our background correction is 0.25

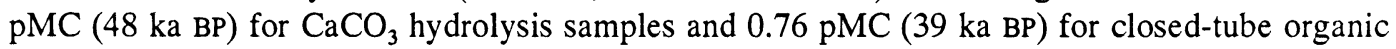
carbon combustion samples.

Samples estimated to be older than $25 \mathrm{ka}$ BP should be pre-etched in dilute acid to remove the surface layer of $\mathrm{CaCO}_{3}$. Although this pre-etching should be performed on all samples, the very small samples often available for AMS dating preclude this as a routine procedure, and, in fact, result in an insignificant improvement in accuracy for samples younger than $25 \mathrm{ka}$ BP at the levels 
of precision obtained routinely. Limestone used for carbonate blanks should be pre-etched in dilute acid and converted to $\mathrm{CO}_{2}$ on the same day to reduce the effect of atmospheric $\mathrm{CO}_{2}$ contamination.

\section{ACKNOWLEDGMENTS}

We would like to thank the members of the Arizona TAMS facility for all their efforts and patience in producing the ${ }^{14} \mathrm{C}$ results presented in this paper: Tim Jull, Doug Donahue, Larry Toolin, Tim Linick (deceased), Art Hatheway and Todd Lange. We would especially like to thank Larry Toolin and Tim Jull for helping us in the initial setup and design of our graphite lines, and for answering our many questions over the years. Special thanks to many members of the Woods Hole Oceanographic Institution: Kathryn Elder, Sheila Griffin, Ellen Druffel, Ann McNichol, Bob Schneider, Amy Witter, Dan McCorkle, John Lee, Gregory Cohen and Carol Ann Kauffman. We are indebted to the glassblowing talents of Bob Anderson. This facility was funded by grants from The National Science Foundation, Office of Naval Research and the Mellon Foundation. This is contribution no. 8136 from the Woods Hole Oceanographic Institution.

\section{REFERENCES}

Bard, E., Arnold, M., Maurice, P. and Duplessy, J. C. 1987 Measurements of bomb radiocarbon in the ocean by means of accelerator mass spectrometry: Technical aspect. Nuclear Instruments and Methods in Physics Research B29: 297-301.

Donahue, D. J., Linick, T W. and Jull, A. J. T. 1990 Isotope-ratio and background corrections For accelerator mass spectrometry radiocarbon measurements. Radiocarbon 32(2): 135-142.

Froelich, P. N. 1980 Analysis of organic carbon in marine sediments. Limnology and Oceanography 25 (3): 564-572.

Griffin, S. and Druffel, E. R. M. 1985 Woods Hole Oceanographic Institution Radiocarbon Laboratory: Sample treatment and gas preparation. Radiocarbon 27(1): 43-51.

Jones, G. A., Jull, A. J. T., Linick, T. W. and Donahue, D. J. 1989 Dating of deep-sea sediments: A comparison of accelerator mass spectrometer and beta-decay methods. Radiocarbon 31(2): 105-116.

Jones, G. A., McNichol, A. P., von Reden, K. F. and Schneider, R. J. 1990 The National Ocean Sciences AMS Facility at Woods Hole Oceanographic Institution. In Yiou, F. and Raisbeck, G. M., eds., Proceedings of the 5th International Conference on Accelerator Mass Spectrometry. Nuclear Instruments and Methods in Physics Research B52: 278-284.

Jull, A. J. T., Donahue, D. J., Hatheway, A. L., Linick, T. W. and Toolin, L. J. 1986 Production of graphite targets by deposition from $\mathrm{CO} / \mathrm{H}_{2}$ for precision accelerator ${ }^{14} \mathrm{C}$ measurements. In Stuiver, $\mathrm{M}$. and Kra, R. S., eds., Proceedings of the 12th International ${ }^{14} \mathrm{C}$ Conference. Radiocarbon 28(2A): 191-197.

LeFeuvre, R. P. and Jones R. J. 1988 Static combustion

of biological samples sealed in glass tubes as a preparation for $\delta^{13} \mathrm{C}$ determination. Analyst 113: 817-823.

Leventhal, J. S. 1976 Stepwise pyrolysis-Gas chromatography of kerogen in sedimentary rocks. Chemical Geology 18: 5-20.

Linick, T. W., Jull, A. J. T., Toolin, L. J. and Donahue, D. J. 1986 Operation of the NSF-Arizona Accelerator Facility for radioisotope analysis and results from selected collaborative research projects. In Stuiver, M. and Kra, R. S., eds., Proceedings of the 12th International ${ }^{14} \mathrm{C}$ Conference. Radiocarbon $28(2 \mathrm{~A})$ : 522-533.

McNichol, A. P., Gagnon, A. R., Jones, G. A. and Osborne, E. A. 1992 Illumination of a black box: Gas composition changes during graphite target preparation for AMS. In Long, A. and Kra, R. S., eds., Proceedings of the 14 th International ${ }^{14} \mathrm{C}$ Conference. Radiocarbon 34(3): 321-329.

Slota, P. J., Jr., Jull, A. J. T., Linick, T. W. and Toolin, L. J. 1987 Preparation of small samples for ${ }^{14} \mathrm{C}$ accelerator targets by catalytic reduction of $\mathrm{CO}$. Radiocarbon 29(2): 303-306.

Swerhone, G. D., Hobson, K. A., van Kessel, C. and Boutton, T.W. 1991 An economical method for the preparation of plant and animal tissue for $\delta^{13} \mathrm{C}$ Analysis. Communications in Soil Science and Plant Analysis 22(3 \& 4): 177-190.

Valastro, S., Jr., Land, L. S. and Varela, A. G. 1979 An improved procedure for wet oxidation of the ${ }^{14} \mathrm{C}$ NBS oxalic acid standard. In Berger, R. and Suess, H. E, eds., Radiocarbon Dating, Proceedings of the 9th International Radiocarbon Conference. Berkeley/Los Angeles, University of California Press: 125-134. 